the chuld's nostrils (the amyl floating on the mucilage) on the least sign of a fit. The child had only one convulsion in the course of the first twenty-four hours of this treatment, and during the three remaining days of the child's life I had no difficulty in keeping those symptoms under control, though I found it necessary to increase, by about one-third, the dose every twenty-four hours.

Case 2 (tubercular meningitis in a boy of six) had been ill for rather more than a fortnight, and for two or three days had been in almost constant convulsion. To alleviate this state, three grains each of the bromide and iodide of potassium had been regularly administered every three hours for forty-eight hours, but without much apparent effect. The nitrite of amyl was ordered to be administered in the same way as in Case 1, and its use was followed by very marked improvement; the twitchings almost entirely ceased, and the child had some hours of sleep. The drug was discontinued on the fourth day, as the larger doses necessary to subdue the fits caused much panting, and the parents, knowing the disease to be almost certainly fatal under any treatment, relaxed their efforts.

Cases 3 and 4 were similar. Both were in very young children, respectively five and nine months old. The convulsions in both cases were traceable to dentition, and in both cases the inhalation of the nitrite of amyl quelled successive fits. The older of the two also took occasionally onefourth of a drop dissolved in spirit, and given on sugar, according to Dr. Ringer's plan. The treatment succeeded.

Case 5 was brought to me as one of rheumatism. The child was one year old. It was a very typical case of spastic rigidity, and the history pointed strongly to dentition as the cause. It occurred to me to give an inhalation of nitrite of amyl. The effect of this was to loosen, as if by magic, the rigid flexion of the fingers and toes, though the friends subsequently informed me that the symptoms returned again later in the day. The child not being sufficiently under observation, I gave the bromide of ammonium internally, but without effect, in place of nitrite of amyl.

I have had several other successful cases similar to the first four that I have given, but which, for the sake of brevity, I omit.

It is strange that since Dr. Lauder Brunton's experiment (Centralblatt für Med. Wissenschaft, 1873), by which it was shown that the convulsions of a frog tetanised by strychnia may be arrested by plunging it into the vapour of nitrite of amyl, so little trial should have been made of this drug in the treatment of tetanus and allied conditions. This is no doubt to be traced to the prevalent belief that nitrite of amyl is a highly dangerous drug, and that its effects are too transitory to be of any real service. Dr. Ringer has, however, shown that, according to his experience, it may be given with safety for months, and that its effects are sufficiently abiding to have a marked influence for good in some cases of epilepsy and in many of the derangements incidental to the change of life in women. In the convulsions of children this drug seems to me to combine in itself the temporary usefulness of chloroform inhalation and the more lasting effect of such sedatives as the bromides. Its administration as an inhalant may further be left in the hands of people of ordinary intelligence, and its smell is agreeable. Of course, so far it can only be regarded as an adjunct in the cure of convulsions to the rational treatment of the morbid state of which the convulsions are mere symptoms-symptoms which, however, are occasionally the direct cause of death by producing asphyxia, and which, more than any other, wring the maternal heart. - Your obedient servant.

Walterton Road, W.

$$
\text { A. E. Bridger, M.D. Edin., B.Sc. Paris. }
$$

\section{"PAYING MEDICAL BILLS OUT OF AN ESTATE:}

To the Editor of THE LANCET.

SIR,- It is not my wish to drag this case again before my professional brethren, but a letter appears in your columns, signed "Audi Alteram Partem," which says that Mr. G. H. Jackson swore in court that he offered to pay us the money, and I swore in court that he never did so. I can only look for the solution of this contradiction in what the defendant admitted in the witness-box, that "his memory was very treacherous."

Tottenham, April, 1882.

\section{SURGICAL EMPHYSEMA.}

\section{To the Editor of THE LANCET.}

SIR,-Mr. Morgan, in his report of Surgical Emphysema, seems to think it improbable that the cough would be sufficient to produce such a state of affairs, and seems to lean more to mechanical agents as a cause of the emphysema; such, for instance, as the passage of an instrument or the penetration of a spicula of bone; although in his case he says, "the swelling was previous to all surgical in. terference."

I would suggest that nothing is more probable than for surgical emphysema to oceur when a large bolus of meat is sticking in the throat, and at the upper or posterior region of the larynx, from the violent expiratory efforts which take place in order that the foreign body may be got rid of. In proof of this theory I would point out that I have seen sur. gical or general emphysema occur where there could be no suspicion of surgical interference, nor any spicula of bone to account for this condition. 1st. From sneezing alone, after taking a three-grain dose of iodide of potassium. This occurred in the case of a powerful muscular Irishman. 2nd. From coughing where sneezing was absent, as in the violent expiratory (?) efforts of whooping-cough. 3rd. From the violent expiratory efforts of parturition, where neither coughing nor sneezing was present. In all of the foregoing cases I have seen the emphysema involve the whole of the head, face, eyelids, and neck, as low as the clavicles in front and the scapula behind.

In my experience examples of general emphysema during parturition are not at all uncommon; and the swollen face, so common in whooping-cough, is in my opinion very largely due to emphysema, although congested vessels no doubt play a part. I am, Sir, very truly yours,

AlberT S. MorToN, M.R.C.S. Eng. Kennington-park-road, S.E., April, 1882.

\section{To the Editor of THE LANCET.}

SiR,-I would demur to Mr. Wyatt's explanation. Em. physema of the neck occurs in children somewhat as he describes; but then they invariably die. Besides, in attributing the rupture of the lesser air-tubes to expiratory efforts he assumes a direct relationship between these efforts and tension of the walls of the air-cells and bronchi. High authorities are agreed with him in so assuming; but I would respectfully suggest that they, like $\mathrm{Mr}$. Wyatt, confound pressure with tension. Mr. Wyatt says: "It seems to me much more probable that the thinner bronchus would give way before the stouter trachea, the pressure on both sides being the same." The pressure is no doubt the same, but the teusion is not; and this confusion of ideas, rather than any physical fact or law, is, I believe, the true basis of the so-called expiratory theory of the production of pulmonary emphysema. That the relationship in question is one of antagonism, the following experiment will show:-Take a cyliuder and piston and, through a small opening into the chamber, pass a portion of a flaccid tube, hermetically sealed, containing air. An expiratory movement of the piston will compress the air in this tube and cause increased pressure on its inner wall, equally distributed throughout, according to the law of fluid pressure; but the part of the tube within the cylinder will nevertheless collapse, and that without the cylinder being put on the stretch. An inspiratory movement will reverse all this.

A minute opening in the trachea, only permeable to air or visible during distension, and such as would quite escape notice when looking for an "apparent rent," would account for the emphyserna in Mr. Morgan's case, and in Mr. IVyatt's too; for it is to be noted that he makes uo mentiın of having. traced the air-blown tissue from the neck to the root of either lung. This was a marked feature in two cases I recently examined post mortem. An infant of eleven months, pros* trate with diarrhœea, suddenly developed bronchial râles with feeble cough. Next day the neck was inflated, and continued so till death, two days later. A child of three years, which had always been the type of health, was seized with diphtheria, and died in three days. Thirty-six hours before death tracheotomy was performed and affurded complete relief to the respiration, which however continued 